\title{
A study on the effect of the clearance on the contact stresses and kinematics of polymeric composite journal bearings under reciprocating sliding conditions
}

\begin{abstract}
The effect of the clearance on the contact stresses and kinematics of a polymeric composite journal bearing is investigated. To this purpose a test rig is devised, which is capable to measure the tribological characteristics of the large-scale composite bearings. Kinematics of the setup is simulated by a 2D FE model. Moreover, to evaluate the contact area between the bearing and shaft, pressure indicator films are used and a simplified 3D model is provided. Simulation results correspond closely to the experiments and it is shown that the clearance variation can have a big impact on the contact stresses distribution.
\end{abstract}

Key words: Polymeric Composite Bearing, Clearance, FEM

\section{Introduction}

The area of tribology deals with the design, friction, wear, and lubrication of interacting surfaces in relative motion. In recent years polymeric composite materials have been used increasingly for such tribological applications. Yet, by now, much of the knowledge on their tribological behavior is often empirical, and very limited predictive capability currently exists [1].

In this article, effects of the clearance between a composite bearing and shaft on the contact stresses and kinematics of a polymeric composite journal bearing are numerically investigated.

Contact problems are very sensitive to minor profile changes in the contact bodies [2]. In addition, dimensional control methods for composites are mainly based on trial and error approaches [3], and tolerance control is not as good as in metal production. Hence, choosing a right clearance for the composite bearing will be very important.

There are few studies about the influence of the designing parameters on the journal bearings application. For example Papadopoulos and Nikolakopoulos have studied the effect of the bearing's wear on the clearance and stability of a metallic rotor journal bearing [3]. Parli Pedersen has studied the influence of the clearance in composite orthotropic disc-pin contact in a fastener assembly. He concluded that Hertz contact formula is a useful tool in the investigation of the pressure distribution in the composite pin-disc contact analysis, but it cannot give detailed information [4].

In this research a large-scale test setup has been devised to determine the tribological behavior of polymeric composite journal bearings subjected to the reciprocating angular movement.

The kinematics of the test setup is simulated with a two-dimensional (2D) plane-strain model and validated with the experimental measurements. Moreover, the contact area is simulated by a simplified three-dimensional (3D) model and evaluated by the experiments with pressure indicator films.

Based on these verifications, the 2D finite element model is developed to investigate the effects of the clearance between the composite bearing and shaft on the operation of the setup and contact stresses in the bearing.

\section{Test setup}

In order to make an appropriate and validated finite element model, proper and accurate experiments are essential. In this article the finite element model is validated with the experimental data extracted by a test rig, which is designed to determine the tribological behavior of large-scale 
journal bearings subjected to the reciprocating angular movement. Figure 1 shows the test rig and its cross-sectional view.

This apparatus has been designed to test composite bearings with inner diameter of about 300 millimeters. The loading conditions, rotation speed, and rotation angle can be changed by user at any time during the test. The friction torque is determined by measuring the force acting on a lever arm connected to the bushing. The tests are driven by a closed-loop servo-hydraulic system. All measuring signals are registered continuously and digitally by means of a data acquisition card. This apparatus provides measurement of the normal and friction force between the bearing and shaft, bearing's temperature during the application, and wear rate of the bearing's surface.

The test is started by applying the vertical force on the housing by the hydraulic actuator, and then the drive piston starts to reciprocate and provides the rotational oscillation to the shaft.

Figure 2 depicts a schematic view of the loading and kinematics of the test rig. During the test $F_{P}$ is assumed to be constant, and vertical. Since the displacement of the bushing remains small, the force in the load cell $F_{L}$ can also be considered vertical. In addition, it is supposed that the friction between the load transmission trolley and the bushing is negligible [5].

Considering the Coulomb law [6] , the coefficient of friction is the ratio of the tangential and normal reaction force components. Here by considering the equilibrium equations, the friction coefficient will be:

$$
\mu=\frac{F_{f}}{F_{N}}=\operatorname{lan} \alpha=\frac{1}{\sqrt{\left(\frac{R_{b}}{R_{I}}\right)^{2}\left(\frac{F_{P}+F_{L}}{F_{I}}\right)^{2} 1}}
$$

If elastic deformation of the load cell and the clearances of its both sides' connections are ignored, the kinematics of the shaft rolling in the bearing can be expressed as:

$$
\left(\frac{d \beta}{d t}-\frac{d O}{d t}\right) /\left(\frac{d p}{d t}-\frac{d \rho}{d t}\right)=\frac{R_{s}}{R_{h}}
$$

\section{2D finite element model}

The test setup is simulated as a simplified two-dimensional quasi-static plane strain model. The shaft is modeled by Mixed Lagrangian-Eulerian method, in which the mesh can have a motion independent of material deformation. Therefore, the motion of the mesh can be designed in accordance with the nature of deformation and thus mesh distortion is avoided on one hand, and the boundaries are updated on the other hand [7]. Figure 3 depicts the boundary conditions and meshing of the 2D plane strain model for the test rig.

It is assumed that the friction coefficient decays exponentially from the static value to the dynamic value according to the formula:

$$
\mu=\mu_{D}+\left(\mu_{S}-\mu_{D}\right) \cdot e^{d_{s} \dot{F}_{s Q}}
$$

Where $\mu_{D} i$ s the dynamic friction coefficient, $\mu_{S}$ is the static friction coefficient, $d_{C}$ is a user-defined decay coefficient, and $\dot{\gamma}_{e q}$ is the slip rate [8]. Based on the experimental data, the parameters of the equation are defined and then the friction coefficient will be calculated correlated to the slip rate.

The test bearing is a composite with a phenolic resin, polyester reinforcing fibers, and PTFE filler for internal lubrication. This bearing is an orthotropic material with the engineering constants shown in table 1. 


\begin{tabular}{|c|l|l|l|l|l|}
\hline$E_{r r}$ & $2.75 \mathrm{GPa}$ & $G_{r t}$ & $1.00 \mathrm{GPa}$ & $v_{r t}$ & 0.165 \\
\hline$E_{t t}$ & $10.00 \mathrm{GPa}$ & $G_{t z}$ & $4.00 \mathrm{GPa}$ & $v_{t z}$ & 0.250 \\
\hline$E_{z z}$ & $10.00 \mathrm{GPa}$ & $G_{r z}$ & $1.00 \mathrm{GPa}$ & $v_{r z}$ & 0.165 \\
\hline
\end{tabular}

Table 1. Engineering constants of the composite bearing, r: Radial coordinate, $t$ : Tangential coordinate, $z$ : Axial coordinate

\section{Verification of the $2 \mathrm{D}$ model with experiments}

The tests were performed on a composite bearing under the conditions shown in table 2:

\begin{tabular}{|l|l|}
\hline Bearing diameter: & $301.1(\mathrm{~mm})$ \\
\hline Bearing thickness & $25(\mathrm{~mm})$ \\
\hline Bearing width & $120(\mathrm{~mm})$ \\
\hline Normal load by loading actuator & $100(\mathrm{kN})$ \\
\hline Driving piston amplitude & $5(\mathrm{~mm})$ \\
\hline Driving piston frequency & $0.5(\mathrm{~Hz})$ \\
\hline Clearance between shaft and bearing & $1.1(\mathrm{~mm})$ \\
\hline $\begin{array}{l}\text { Clearance between the load cell pins and } \\
\text { correlated bushing }\end{array}$ & $0.1(\mathrm{~mm})$ \\
\hline
\end{tabular}

Table 2. Test conditions

From the experimental data the parameters of equation 3 are defined. For the selected bearing, the static coefficient of friction is 0.145 , the dynamic coefficient of friction for the infinite slip rate is 0.115 , and the user-defined coefficient based on the experimental information is 1000 .

Figure 4 compares the obtained friction and normal forces from the experimental measurements and numerical simulations. Due to the static coefficient of friction at the start of each cycle the friction force graph shows a spike, and when sliding occurs, it decreases. It is obvious that when the direction of the rotation changes, the direction of the friction force also changes. These figures show that there is a very good agreement between numerical and experimental results. At the start of each cycle when rolling contact occurs, the friction force raises up to $14.5 \mathrm{kN}$ and then it decreases to $11.5 \mathrm{kN}$ in the sliding condition. In the clockwise rotation of the shaft, the normal force rises from $96.90 \mathrm{kN}$ in the rolling state to $97.70 \mathrm{kN}$ in the sliding state, and in the counterclockwise rotation of the shaft, it decreases from $101.20 \mathrm{kN}$ to $101.10 \mathrm{kN}$. These values also correspond closely to the experimental measurements.

Figure 5 shows that the simulation results of the horizontal displacement of the bushing precisely correspond with the test results. At the moment that the shaft motion tends to overcome the static friction force, the bearing sticks to the shaft. At this moment the bushing system moves forward or backward depending on the direction of rotation. Once the contact condition changes from rolling to sliding, the bearing slides back and the shaft slides against the bearing in a fixed position. The horizontal displacement of the bushing varies between +0.1 and $-0.1 \mathrm{~mm}$.

\section{Pressure distribution area}

In the second stage, it was necessary to verify the accuracy of the simulation results for the contacting area. While the simulation results for the friction and normal forces correspond very well to the experimental measurements, it is necessary to verify the accuracy of the simulation results for the contact area. Indeed the friction and normal forces are the integration of the contact stresses. To prove the accuracy of the contact models, not only the integration of the contact stresses must be equal to the measured experimental forces, but also the area of the stress distribution must adapt to the experiments. 
To this purpose, a pressure indicator film was employed. This pressure indicator film reveals the distribution and magnitude of pressure between two contacting, mating or impacting surfaces. The pressure indicating sensor film is sufficiently thin $(0.2 \mathrm{~mm})$ which enables it to conform to curved surfaces. It is suitable for tight spaces not accessible to conventional electronic transducers.

The film is a Mylar based film that contains a layer of tiny microcapsules. The application of force upon the film causes the microcapsules to rupture, producing an instantaneous and permanent high resolution "topographical" image of pressure variation across the contact area [9].

By placing the film between two contacting bodies and applying and removing pressure, the film reveals the pressure distribution profile that occurred between the two surfaces. Conceptually similar to Litmus paper, the color intensity of the film is directly related to the amount of pressure applied to it. The greater the pressure, the more intense the color.

In this test the pressure indicator film is used only to verify the area of the contact zone. Because each type of films can indicate a certain pressure range, five different films are used to explore the entire range of the contact pressure between the composite bearing and the shaft. Based on the indicating pressure level, the films are named as Zero, Ultra low, Super low, Low, and Medium film. The films are cut to strips, are assembled parallel to each other, and then are placed between the shaft and bearing. Two different tests are provided in this step. In the first test (case 1) the clearance between the bearing and shaft is $3.8 \mathrm{~mm}$, and in the second test (case 2) the clearance is $0.82 \mathrm{~mm}$. Figure 6 shows the test procedure, and table 3 depicts the details of the test conditions and the characteristics of the pressure indicator films.

\begin{tabular}{|l|l|l|}
\hline \multicolumn{3}{|c|}{ Test conditions } \\
\hline & Case 1 & Case 2 \\
\hline Bearing diameter & $303.8(\mathrm{~mm})$ & $300.82(\mathrm{~mm})$ \\
\hline Bearing width & $120(\mathrm{~mm})$ & $60(\mathrm{~mm})$ \\
\hline Bearing thickness & $25(\mathrm{~mm})$ & $25(\mathrm{~mm})$ \\
\hline Shaft diameter & $300(\mathrm{~mm})$ & $300(\mathrm{~mm})$ \\
\hline Clearance & $3.8(\mathrm{~mm})$ & $0.82(\mathrm{~mm})$ \\
\hline Vertical load & $320(\mathrm{kN})$ & $56(\mathrm{kN})$ \\
\hline \multicolumn{3}{|l|}{ Pressure indicator films } \\
\hline Film name & Indicating Pressure level \\
\hline Zero & $0.05-2(\mathrm{MPa})$ \\
\hline Ultra low & $0.2-0.5(\mathrm{MPa})$ \\
\hline Super low & $0.5-2.5(\mathrm{MPa})$ \\
\hline Low & $2.5-10.0(\mathrm{MPa})$ \\
\hline Medium & $10.0-50.0(\mathrm{MPa})$ \\
\hline
\end{tabular}

Table 3. Test conditions and different ranges that films can indicate

Since the deformation of the bushing and shaft is negligible and here the evaluation of the contact stress distribution is the main objective, this experiment is simulated by a simplified finite element model shown in figure 7. This model includes a rigid shaft, rigid bushing, deformable composite bearing, and a deformable pressure indicator film. The pressure film is necessary to be included in the model because it changes the clearance between the bearing and shaft. The small free spaces between the pressure indicator films are not applied in the model, and the pressure sensor is simulated as a single strip. The vertical load is applied on the bushing, and the shaft is fixed.

Figures 8 shows the experimental and numerical results for the contact stress distribution on the pressure indicating films. The maximum length of the colored areas on the pressure sensor films are $173 \mathrm{~mm}$ for case 1, and $209 \mathrm{~mm}$ for case 2, which are initiated on the zero film. These values are 170 and $204 \mathrm{~mm}$ for the simulation results (figure 10). Comparing these results gives a deviation less than 2 percent. Considering the scale of the test setup and parameters like geometrical tolerances, dimensional tolerances, loading misalignments, and other parameters this deviation is quite insignificant and results are in a very good agreement. Since in the contact modeling 2D 
plane-strain elements correspond very well to 3D continuum elements [10], the agreement between the experiments and 3D simulations provides also approbation for the 2D models.

\section{Influence of the clearance}

As seen in the previous section, the simulation results closely correspond to the experimental data. Based on these verifications, the finite element model is extended to investigate the effect of the clearance (play) between the composite bearing and the shaft on the kinematics of the setup and contact stresses on the bearing. The analyses were performed for the clearance ranges between 0.1 $\mathrm{mm}$ and $4.1 \mathrm{~mm}$, with a step size of $0.4 \mathrm{~mm}$. Even though the lower and upper bounds for the clearance are not practical choices, they are studied to evaluate the ratio of the clearance impact.

Figure 9 shows the effect of the clearance size on the friction force. As seen, the clearance magnitude has not significant effect on the momentum of the friction force. While the magnitude of the friction force is not highly influenced by the clearance, figures 10 and 11 show that the frictional shear stress on the bearing is highly dependent on the clearance size. These figures show the distribution of the shear stress in the sliding condition while the shaft rotates in clockwise $(\mathrm{CW})$ and counterclockwise (CCW) directions.

By increasing the clearance size, the stress level increases and the contact area decreases. The effect of the clearance is more noticeable for the tighter clearances. By changing the clearance from 0.1 to 0.5 , the maximum value of the shear stress increases about $0.26 \mathrm{MPa}$. Then, by increasing the clearance from 0.5 to 0.9 , the maximum shear stress increase about $0.14 \mathrm{MPa}$. This value is about $0.1 \mathrm{MPa}$ when the clearance changes from 0.9 to $1.3 \mathrm{~mm}$.

As expected, the normal pressure on the bearing shows the same behavior as the frictional shear stress. Figures 12 and 13 respectively show the normal pressure on the bearing surface for clockwise rotation of the shaft and counterclockwise rotation of the shaft. By changing the clearance from $0.1 \mathrm{~mm}$ to $4.1 \mathrm{~mm}$, the maximum pressure changes about $8.2 \mathrm{MPa}$.

Figure 14 shows the variation of the sliding angle by changing the clearance size. Like previous parameters, the clearance has a nonlinear effect on the sliding angle. The major effect is about 2 degrees for the play from 0.1 to 0.5 . If the clearance becomes bigger than 1.3 , the rolling angle does not change noticeably.

Unlike the other parameters, the horizontal displacement of the busing is linearly dependent to the clearance size. In figure 15 it is seen that horizontal motion of the bushing increases about 0.023 $\mathrm{mm}$ by adding $0.4 \mathrm{~mm}$ to the clearance.

\section{Conclusion}

The application of a large scale polymeric composite journal bearing under the reciprocating angular movement has been studied. This study includes two major steps. At first, a polyester based composite bearing has been tested under $100 \mathrm{kN}$ load. Besides the experimental investigations, a 2D finite element model has been built up to evaluate the kinematics of the setup and contact stresses on the bearing. The bearing has been simulated as an orthotropic material, and the static and dynamic friction conditions have been applied through an exponential function. Simulation results are in a very good agreement with the experimental outputs, and show that the combination of Lagrange and Euler formulations is a very convenient tool to simulate journal bearing applications. In the second step, a test has been planned to study the contact area between the bearing and the shaft. An arrangement of pressure indicator films has been used to measure the contact area. This test has also been simulated with a simplified 3D FEM model. The contact area obtained from the experiments and simulations, closely correspond and show that the FEM modeling results are highly reliable. Based on these verifications, the 2D FEM model is extended to investigate the effect of the clearance on the kinematics of the setup and contact stresses on the bearing. The results 
show that the contact stress distribution is highly influenced by minor variation of the clearance, when the clearance is nominally small.

Considering that the maximum contact stress is highly dependent on the clearance size and failure of the bearing is dependent on the stress level, it is very important to choose an appropriate clearance for composite journal bearings. 


\section{References}

[1] Friedrich K, Schlarb AK. Tribology of Polymeric Nanocomposites.Tribology and Interface Engineering Series, No. 55. first ed: Elsevier; 2008.

[2] Barber JR, Ciavarella M. Contact mechanics. International Journal of Solids and Structures. 2000;37:29-43.

[3] Papadopoulos CA, Nikolakopoulos PG, Gounaris GD. Identification of clearances and stability analysis for a rotor-journal bearing system. Mechanism and Machine Theory. 2008;43:411-26.

[4] Pedersen P. On the influence of clearance in orthotropic disc-pin contacts. Composite Structures. 2007;79:554-61.

[5] Rezaei A, Ost W, Paepegem WV, Degrieck J, Debaets P. Experimental study and numerical simulation of the large-scale testing of polymeric composite journal bearings: Two-dimensional modeling and validation. Tribology Letters. 2009;37:12.

[6] Persson BNJ. Sliding friction: Physical principles and applications. 2nd edition ed: Springer; 1998

[7] Belytschko T, Liu WK, Moran B. Nonlinear Finite Elements for Continua and Structures John Wiley \& Sons; 2000.

[8] Oden JT, Martins JAC. Models and computational methods for dynamic friction phenomena. Computer Methods in Applied Mechanics and Engineering. 1985;52:528-634.

[9] Pressurex. Tactile pressure indicating sensor film. 2010, January: http://sensorprod.com [10] ABAQUS6.9 Documentation, Abaqus benchmarks manual, section 1.1.11. 2010 


\section{Figure captions}

Figure 1. Large-scale tribotester for radial composite bearings.

Figure 2 . Schematics of the forces and kinematics of the setup. a: Acting forces, b: Kinematics.

Figure 3 . 2D finite element model.

Figure 4. Experimental measurements and numerical simulation results for the friction and normal forces between the composite bearing and shaft.

Figure 5. Horizontal displacement of the bushing,

Figure 6. Implementing of the pressure indicator films between the bearing and the shaft.

Figure 7. 3D FE model for study of the contact area.

Figure 8. Pressure distribution indicated by pressure sensor films and calculated with the FEM.

Figure 9. Effect of the clearance on the friction force.

Figure 10. Effect of the clearance on the frictional shear stress (clockwise rotation of the shaft).

Figure 11. Effect of the clearance on the frictional shear stress (counterclockwise rotation of the shaft).

Figure 12. Effect of the clearance on the normal stress (clockwise rotation of shaft).

Figure 13. Effect of the clearance on the normal stress (counterclockwise rotation of shaft).

Figure 14. Effect of the clearance on the sliding angle.

Figure 15. Effect of the clearance on the horizontal displacement of the bushing. 


\section{Figure 1}

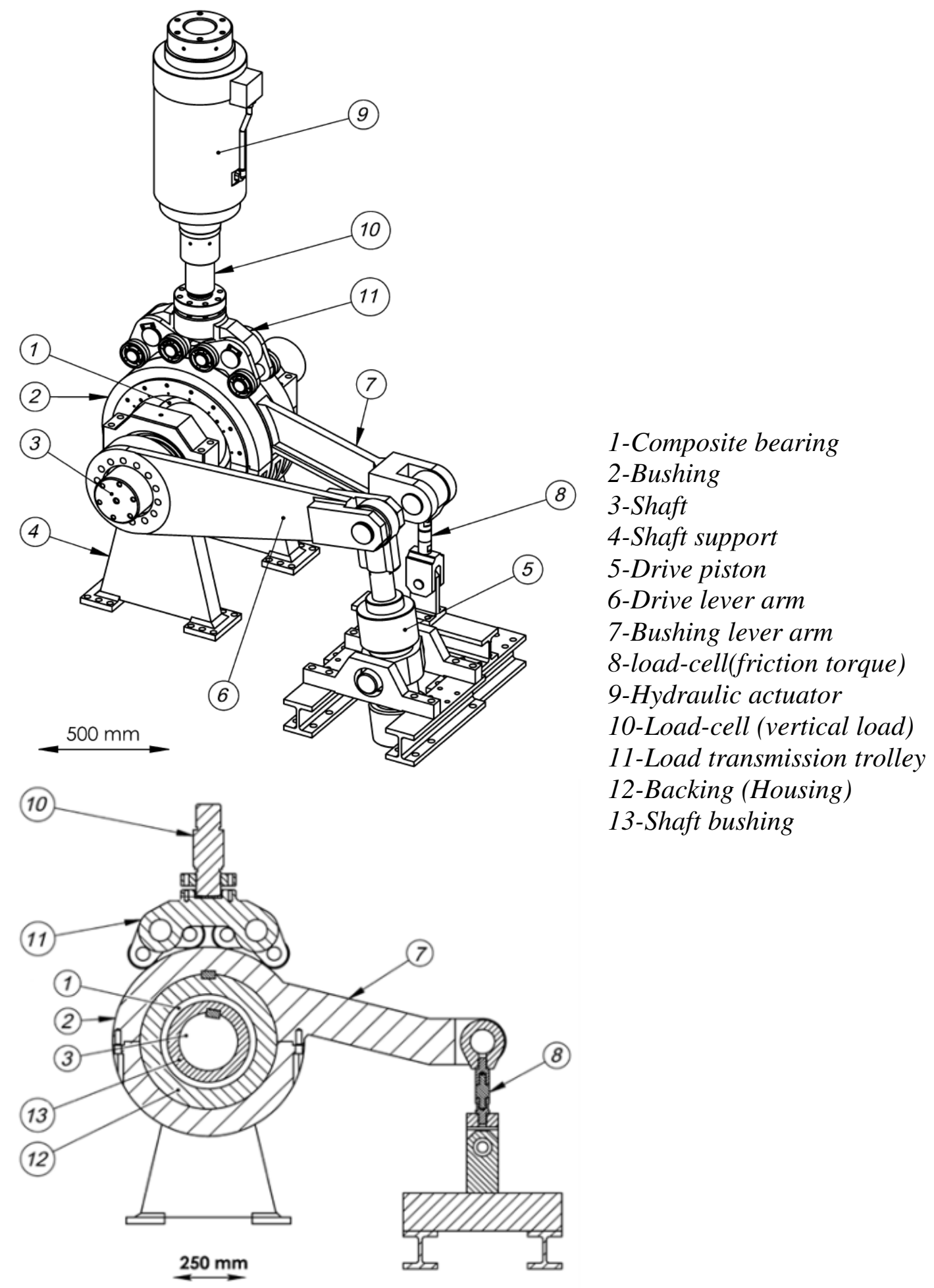




\section{Figure 2}

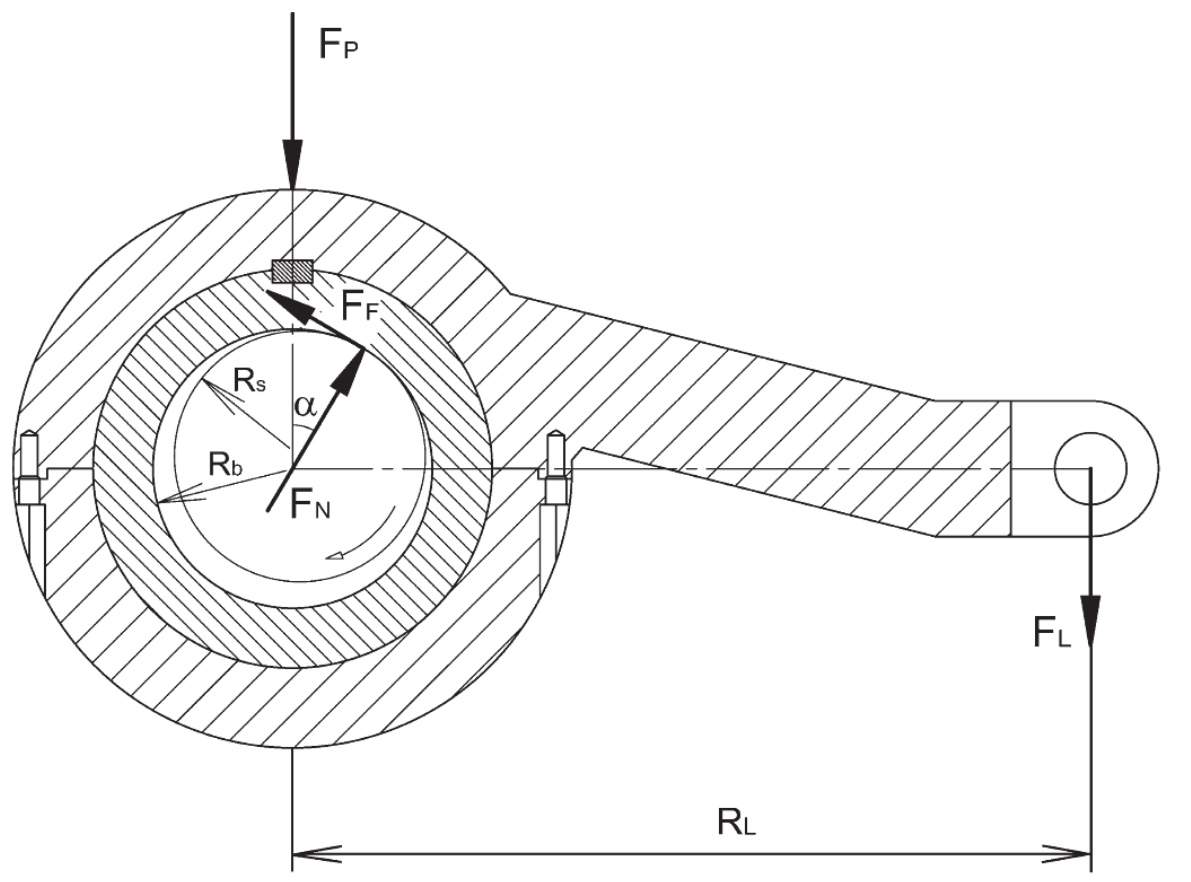

$\mathrm{F}_{\mathrm{P}}$ : Loading actuator force

$\mathrm{F}_{\mathrm{F}}$ : Friction force

$\mathrm{F}_{\mathrm{N}}$ : Normal force

$\mathrm{F}_{\mathrm{L}}$ : Force on the load-cell

$\mathrm{R}_{\mathrm{S}}$ : Shaft radius

$\mathrm{R}_{\mathrm{b}}$ : Bearing radius

$\mathrm{R}_{\mathrm{L}}$ : Distance between the action points of $F_{P}$ and $F_{L}$

$\alpha$ : Sliding angle

(a)

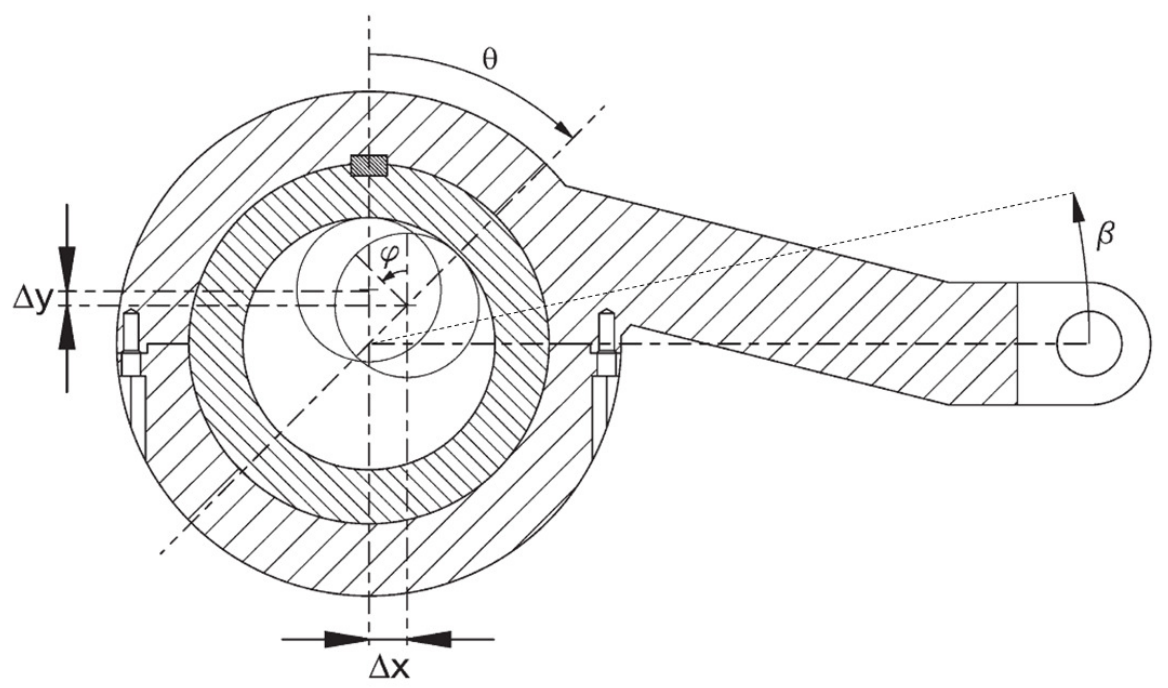

$\theta$ : Rotation of the shaft around the bearing's center

$\varphi$ : Rotation of the shaft around its own center

$\beta$ : Rotation of the bushing around the bearing's center

$\Delta \mathrm{x}$ : Horizontal displacement of the bushing

$\Delta y:$ Vertical displacement of the bushing

(b) 
Figure 3

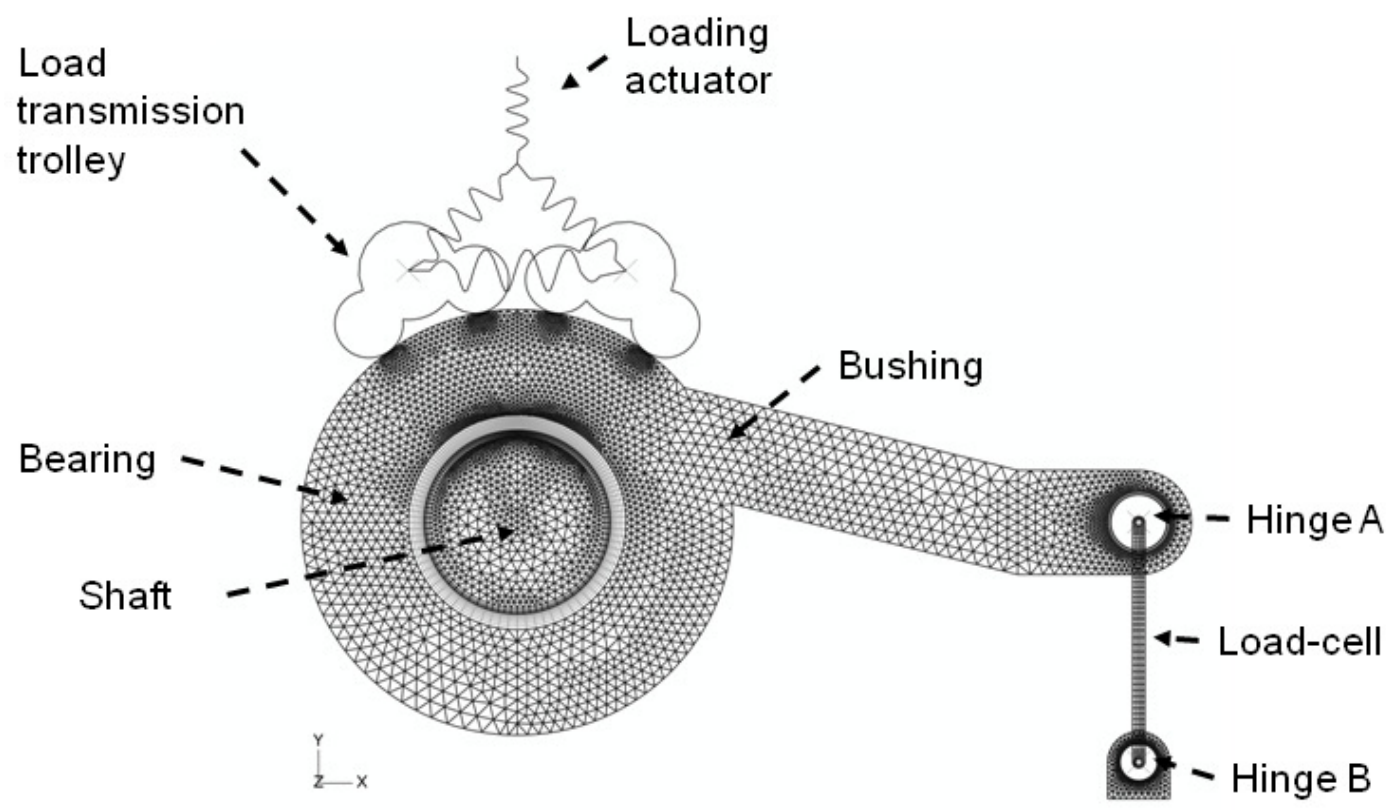


Figure 4
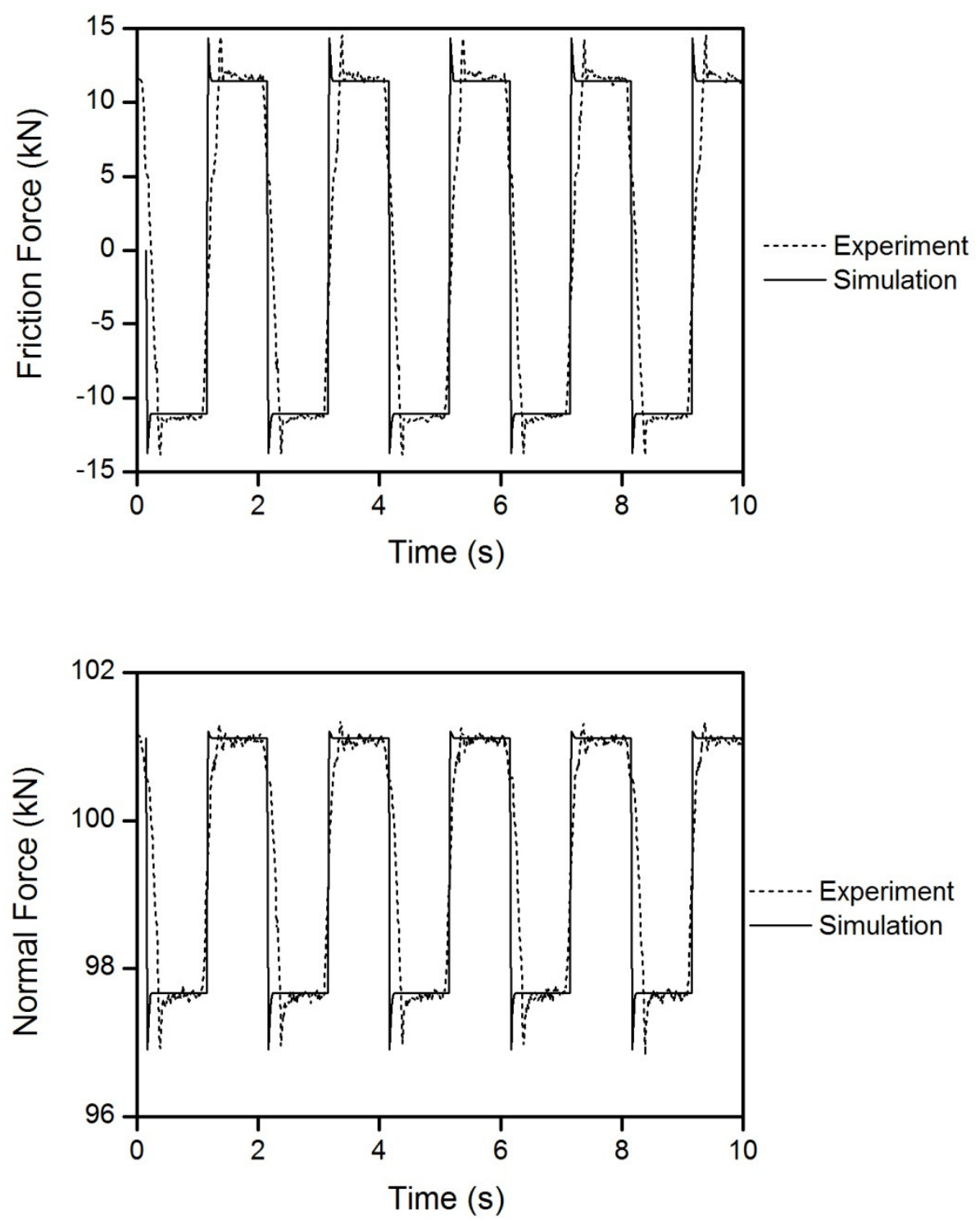
Figure 5

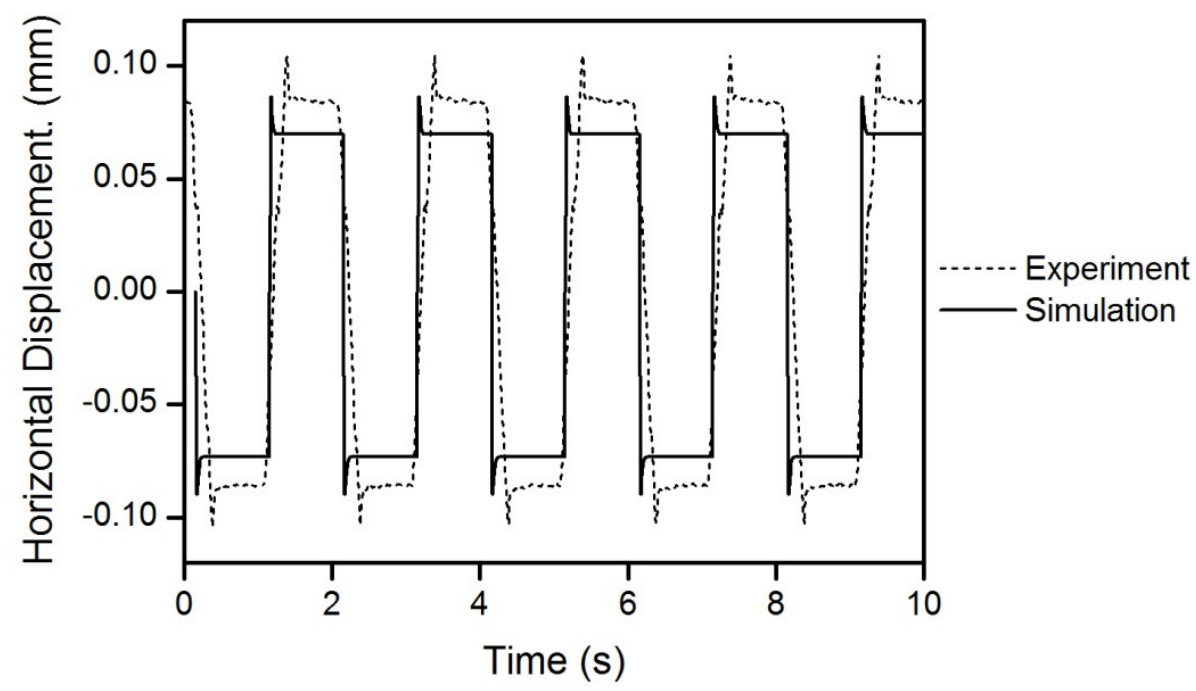


Figure 6

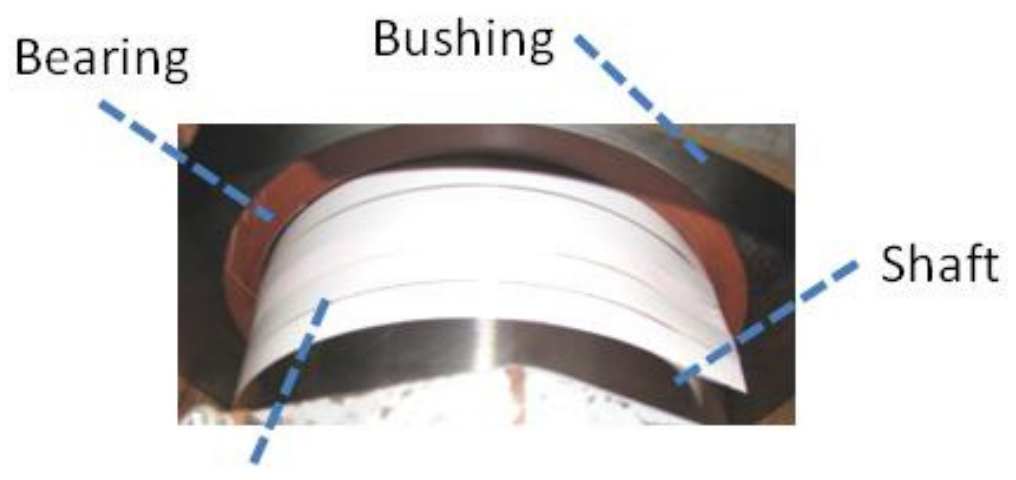

Pressure indicatorfilms 
Figure 7

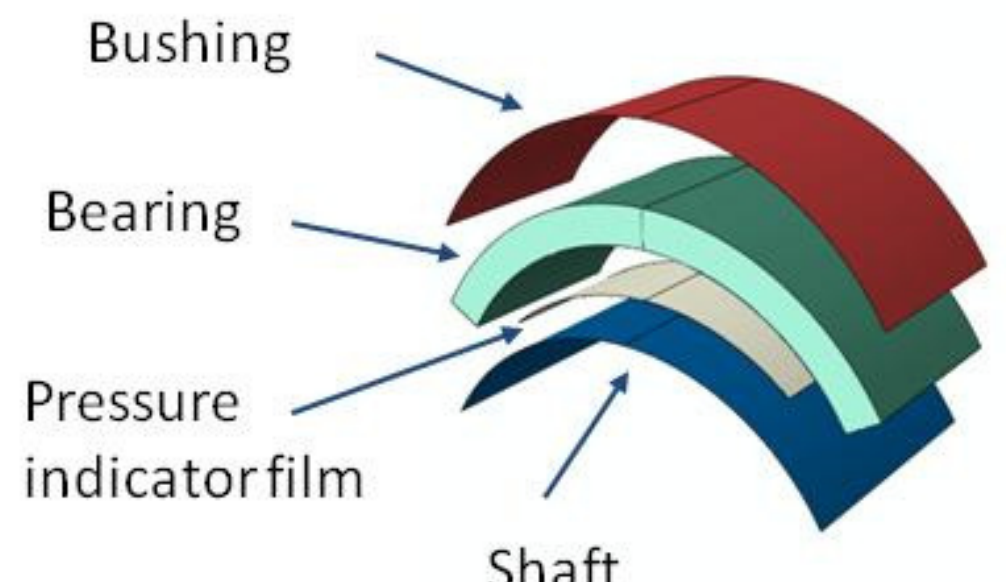

Shaft 
Figure 8
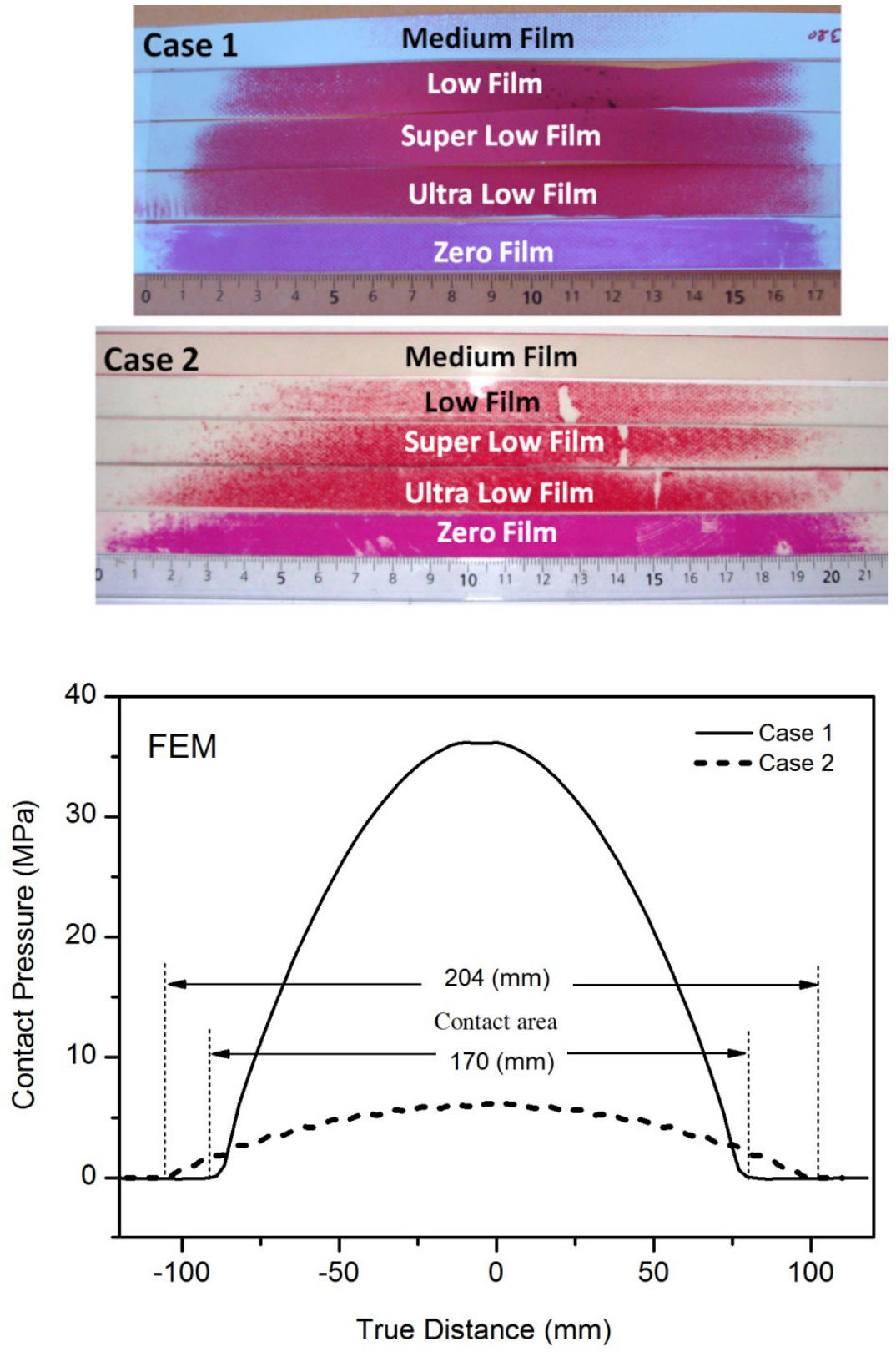
Figure 9

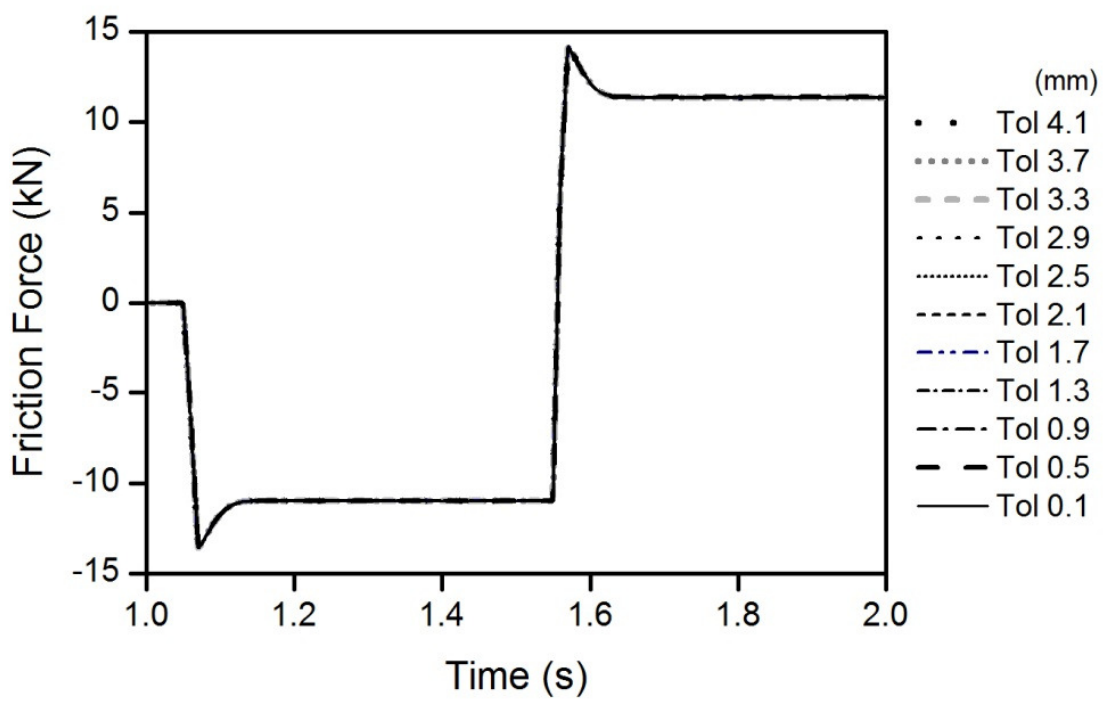


Figure 10

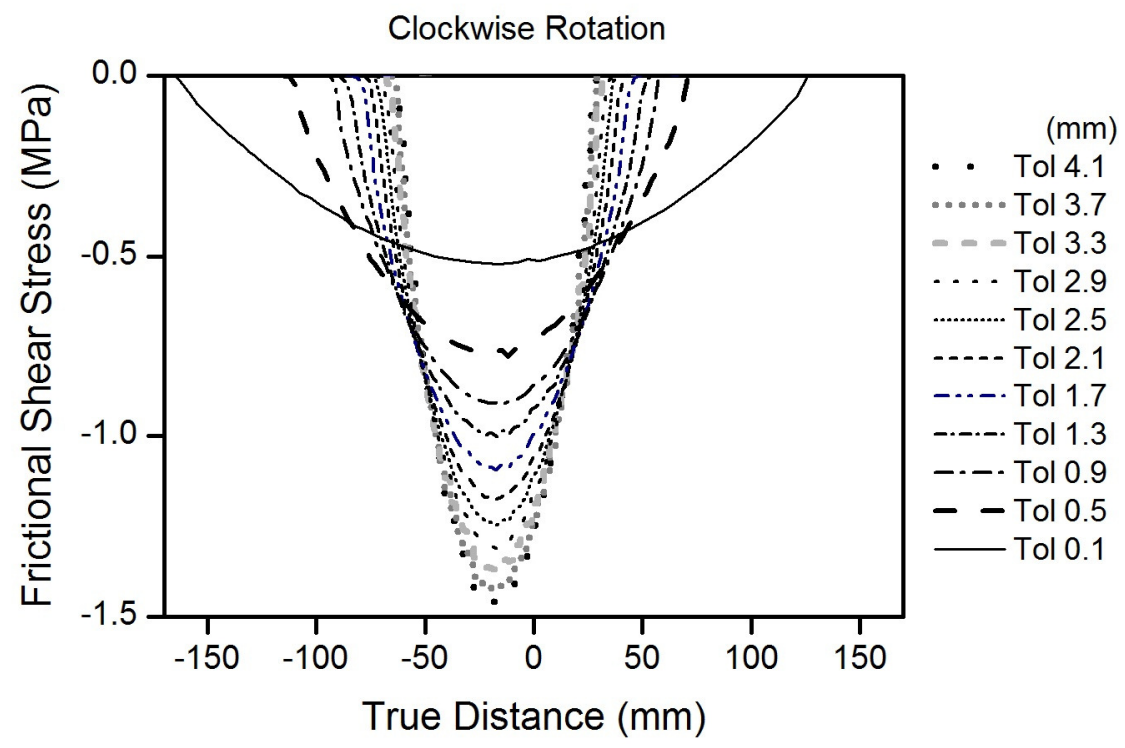


Figure 11

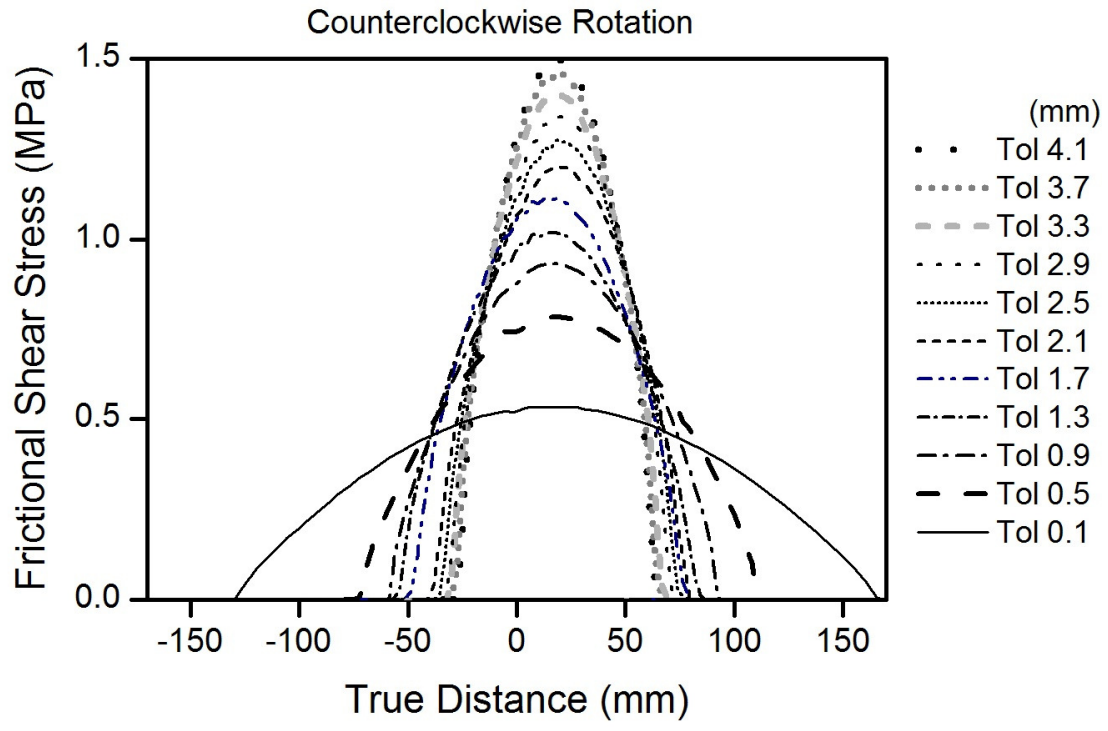


Figure 12

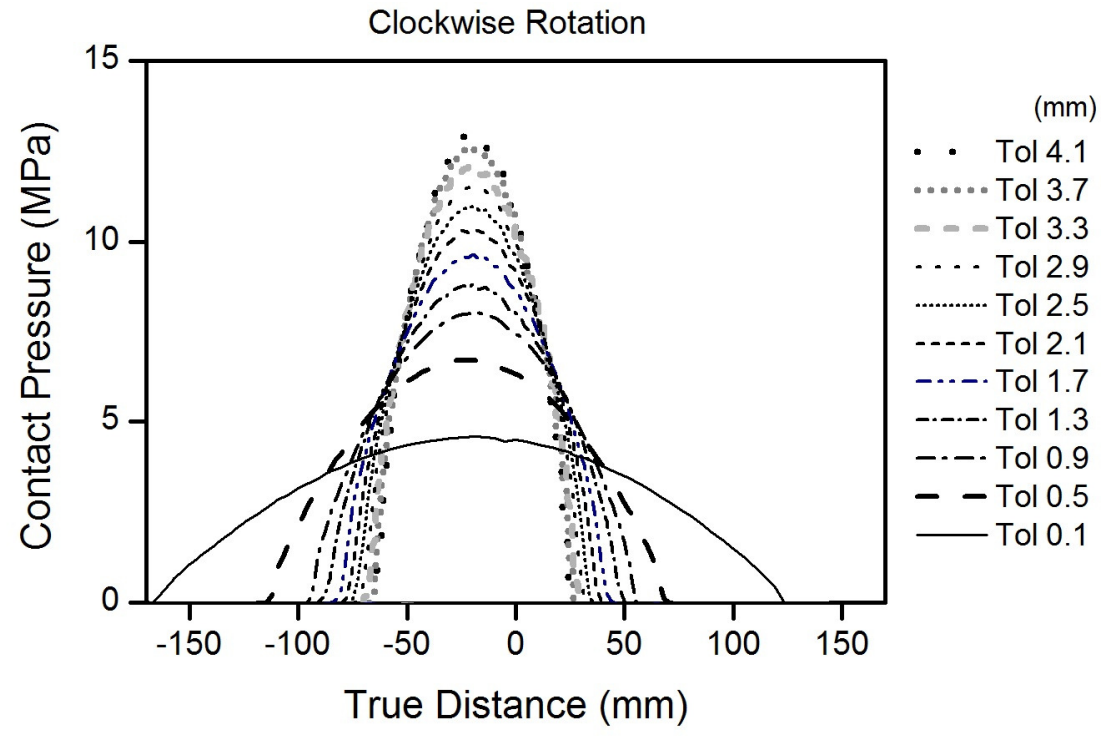


Figure 13

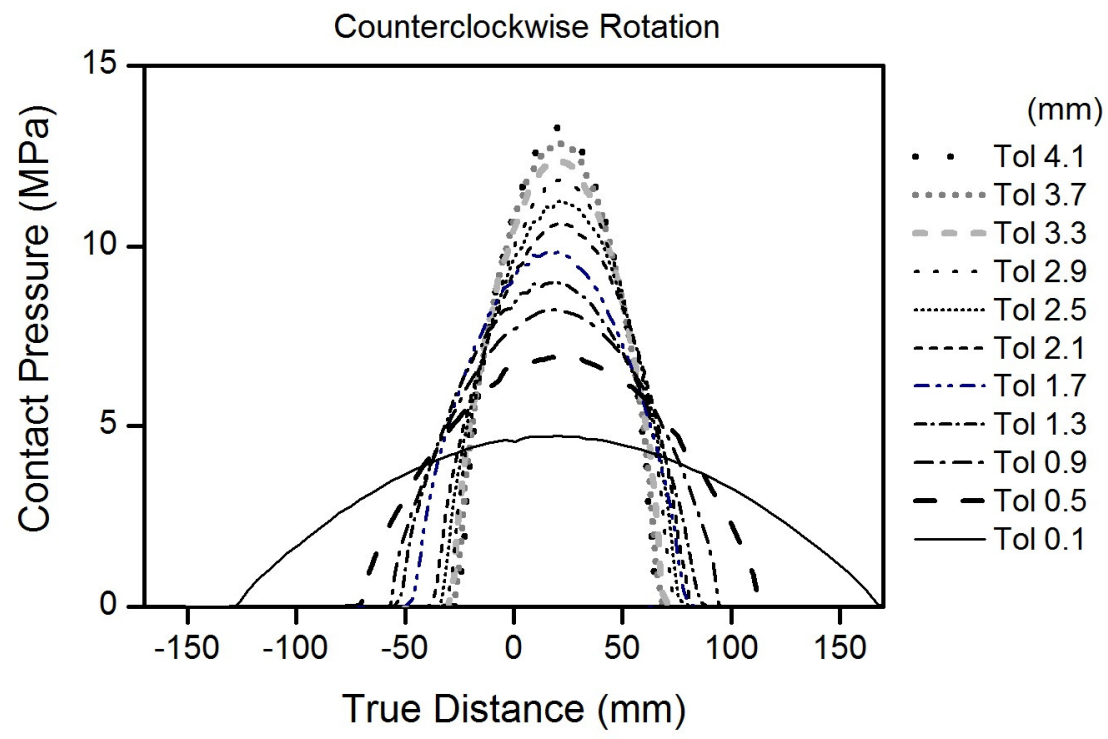


Figure 14

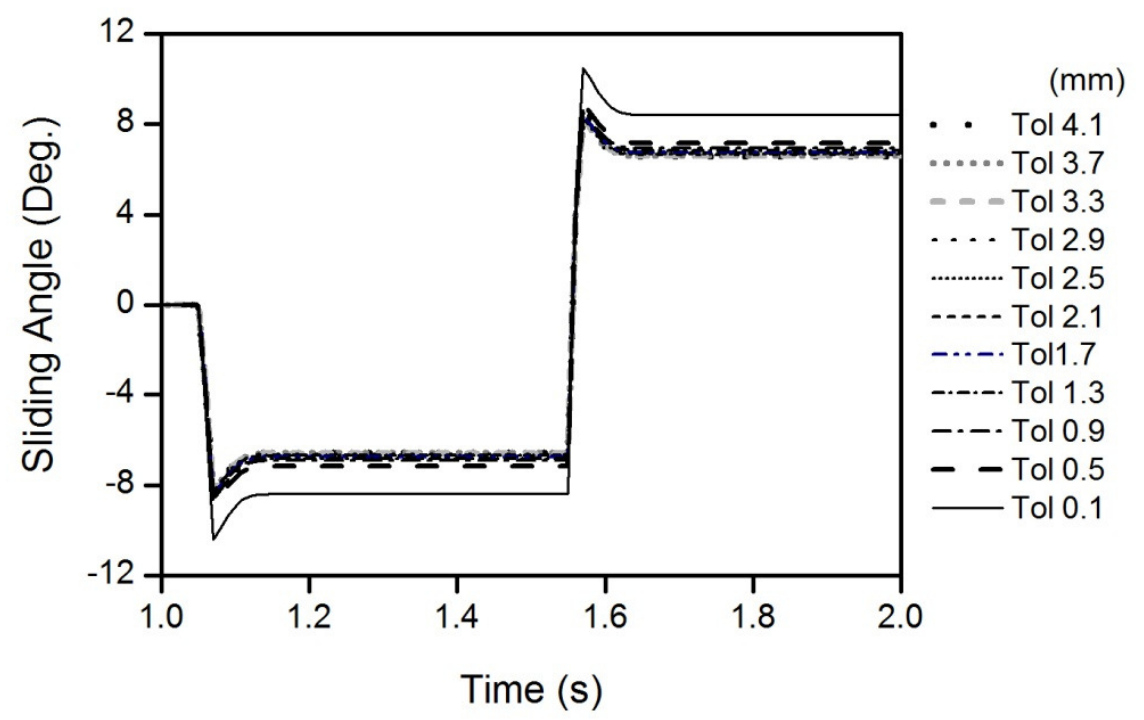


Figure 15

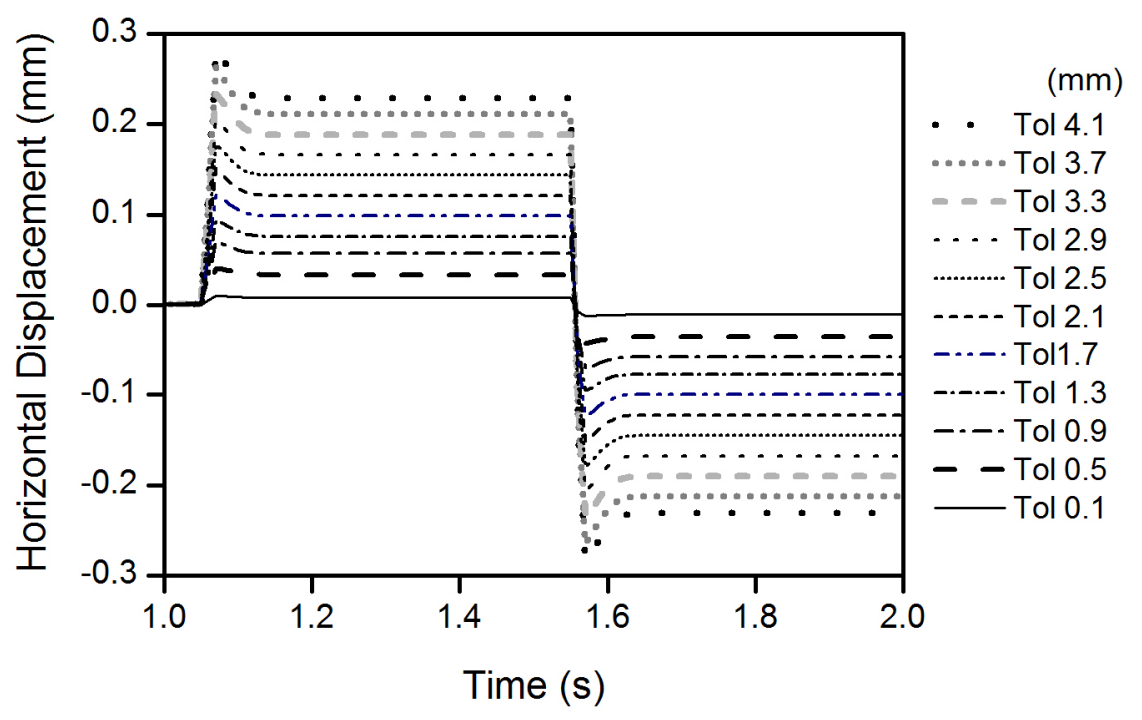

